This item was submitted to Loughborough's Research Repository by the author.

Items in Figshare are protected by copyright, with all rights reserved, unless otherwise indicated.

\title{
Two-dimensional clay nanosheet-reinforced polytetrafluoroethylene composites and their mechanical/tribological studies
}

PLEASE CITE THE PUBLISHED VERSION

https://doi.org/10.1016/j.mtcomm.2021.102026

PUBLISHER

Elsevier

VERSION

AM (Accepted Manuscript)

\section{PUBLISHER STATEMENT}

This paper was accepted for publication in the journal Materials Today Communications and the definitive published version is available at https://doi.org/10.1016/j.mtcomm.2021.102026.

LICENCE

CC BY-NC-ND 4.0

\section{REPOSITORY RECORD}

Msalehdan, Tahereh, Mehdi Eskandarzade, Abolfazl Tutunchi, Byungki Kim, Harry Questa, Mahdi Mohammad-Pour, and Mehdi Shahedi Asl. 2021. "Two-dimensional Clay Nanosheet-reinforced Polytetrafluoroethylene Composites and Their Mechanical/tribological Studies”. Loughborough University. https://hdl.handle.net/2134/13526207.v1. 
3 Tahereh Msalehdan ${ }^{1}$, Mehdi Eskandarzade ${ }^{2}$, Abolfazl Tutunchi $^{1 *}$, Byungki Kim ${ }^{3}$, Harry Questa ${ }^{4}$,

4 Mahdi Mohammadpour ${ }^{4}$, Mehdi Shahedi Asl ${ }^{2}$

$5 \quad{ }^{1}$ Department of Materials Engineering, Institute of Mechanical Engineering, University of Tabriz, Tabriz 51666-

16444, Iran

${ }^{2}$ Department of Mechanical Engineering, Faculty of Engineering, University of Mohaghegh Ardabili, Ardabil

${ }^{3}$ School of Mechatronics Engineering, Korea University of Technology and Education, Cheonan 31253, Republic of

Korea

${ }^{4}$ Wolfson School of Mechanical, Electrical and Manufacturing Engineering, Loughborough University, UK

\section{Abstract}

13 Polytetrafluoroethylene (PTFE) polymer is used extensively in industry as a solid lubricant

14 because of its lack of reactivity with most industrial materials. However, PTFE has a low abrasive

15 resistance, limiting its application. In this study, the mechanical and tribological characteristics of

16 PTFE-based composites with the addition of clay nano-sheets (CNSs) were investigated. Clay

17 nano-sheet-PTFE composites (CNSTCs) containing 1, 3, and 5 wt. \% of CNSs were prepared by

18 employing a compression moulding method. To investigate the tribological characteristics and

19 wear mechanism of CNSTCs, a pin-on-ring test, scanning electron microscopy (SEM), and optical

20 microscopy (OM) were employed. The results indicate that adding CNSs decreased the friction

21 coefficient substantially. Additionally, the wear rates decreased from $1.09 \times 10^{-3} \mathrm{~mm}^{3} /(\mathrm{Nm})$ in the

22 pure PTFE sample to $0.32 \times 10^{-5} \mathrm{~mm}^{3} /(\mathrm{Nm})$ for the $5 \mathrm{wt}$. $\%$ CNSs filled composite. This shows that 
23 the wear rate of the PTFE-based composite is reduced by up to 340 times with the addition of 5

24 wt. \% CNSs. SEM and OM observations revealed that CNSs could inhibit the growth of 25 microcracks in CNSTCs and change the wear mechanism from adhesive to abrasive. Furthermore, 26 adding CNSs resulted in a more uniform and thinner transition film formation, with reduced 27 secondary wear and friction. The effects of the size, percentage, and type of embedded fillers were 28 compared with previous studies. The analysis revealed that in addition to competitive cost and 29 high availability, CNSs have superior characteristics and can be employed to enhance the 30 tribological properties of PTFE nanocomposites.

31 Keywords: Clay Nano-Sheets, Tribology, Polytetrafluoroethylene, Nanocomposite, Wear

32 Resistance

34 Corresponding author: Dr. Abolfazl Tutunchi (ab.tutunchi51@tabrizu.ac.ir)

35 Department of Materials Engineering, Institute of Mechanical Engineering, University of Tabriz,

36 Tabriz 51666-16444, Iran. Tell: 0098 (41) 33340083 
40 Improvement in the life cycle of contacting pairs has attracted global research interest and can be

41 achieved through the enhancement of tribological properties. Insufficient control of wear and

42 friction in sliding parts not only causes earlier failures in one or both parts, but is also the leading

43 cause of energy dissipation in many systems. It is estimated that the direct and non-direct cost of

44 tribological problems could be $2-7 \%$ of the Gross Domestic Product (GDP) of most developed

45 countries [1-3].

46 Remarkable developments in polymer manufacturing processes have been made, yielding high

47 strength-to-weight ratios, good processability, and favourable characteristics. Polymeric materials

48 are now considered an attractive alternative to conventional metallic counterparts, and have

49 already been used in wear and friction applications [4-7]. Pure polymers do not generally have

50 desirable tribological characteristics; however, mixing them with other materials can improve their

51 frictional properties. There are many reports of progress in using polymeric composites for

52 engineering components such as gears, supports, ball bearings, tyres, rollers, plastic belts, clutch

53 and brake pads, bone joints, and artificial teeth [8-11].

54 Polytetrafluoroethylene (PTFE, also known as "Teflon") is a white and solid thermoplastic

55 material with high viscosity and molecular weight. It is a stable thermoplastic substance and is

56 considerably resistant at elevated temperatures owing to the strong carbon-fluorine bonds in its

57 molecular structure. Owing to its excellent electrical insulation properties, chemical neutrality, and

58 low friction coefficient at various working temperatures, PTFE has found numerous applications

59 in fields ranging from electronic and electrical equipment to the aerospace and biomedical 60 industries [12-14]. 
61 Despite these advantages, PTFE suffers from poor wear resistance, which limits its application in

62 demanding engineering and tribological systems. Various metallic or ceramic fillers (e.g., fibres,

63 sheets, or particles) have been added to PTFE-based composites [6, 15-19] to modify their

64 mechanical behaviour and enhance their abrasion resistance.

65 Previous studies have revealed that using micron-sized fillers in Teflon composites can improve

66 their wear resistance. However, such fillers incur limitations including high grain size, high weight

67 to volume percent, increased friction coefficient, disruption of transition film formation, and

68 corrosion of opposing surfaces [20,21]. To solve these problems, nanosized additives are used to

69 improve the mechanical and physical properties of PTFE composites [20, 22-24]. Gao et. al.

70 investigated the tribological properties of a PTFE matrix filled with different amounts of polyether

71 ether ketone (PEEK) $(38 \mu \mathrm{m})$ and nano- $\mathrm{ZrO}_{2}(20 \mathrm{~nm})$ [18]. The study revealed that the friction

72 coefficient and the volume wear rate of the PTFE composites were effectively reduced by adding

73 nano- $\mathrm{ZrO}_{2}$ and PEEK, separately or together. The best tribological properties were obtained when

74 the composites were filled with 5-8 vol.\% nano- $\mathrm{ZrO}_{2}$. In another study [20], $\mathrm{ZnO}$ nanoparticles

$75(50 \mathrm{~nm})$ were mixed with a PTFE matrix, and the results showed up to 100 times greater abrasion

76 resistance by adding $15 \mathrm{wt} . \%$ nano-sized zinc oxide. To enhance the wear performance of a PTFE

77 matrix, 20 wt. $\% \mathrm{Al}_{2} \mathrm{O}_{3}$ nanoparticles $(\sim 38 \mathrm{~nm})$ were added, and a 600 times improvement was

78 achieved $[25,26]$. Cai et. al. [22] added 2 wt.\% of single-walled carbon nanotubes (SWCNTs) to

79 a PTFE matrix and showed that the ultimate engineering stress and true stress were improved by

80 approximately $50 \%$ and $200 \%$, respectively. Additionally, by adding 5 wt. $\%$ of SWCNT, wear

81 resistance was enhanced by around 20 times, and the friction coefficient was raised by $\sim 50 \%$ [27].

82 Lin et al. studied the friction coefficient and wear resistance of PTFE-based composites reinforced

83 with $\mathrm{SiC}, \mathrm{Si}_{3} \mathrm{~N}_{4}, \mathrm{SiO}_{2}(\sim 0.5-5 \mu \mathrm{m})$, or h-BN $(\sim 3-5 \mu \mathrm{m})$ ceramic particles [15]. They found that 
84 the crystallinity of the PTFE matrix was promoted by applying these ceramic fillers. Furthermore,

85 this study proved that the brittleness of the ceramic particles could play a vital role in the anti-wear

86 performance of PTFE composites.

87 Since the early 1990s and the successful addition of clay to nylon 6 by Toyota [28], various

88 industrial sectors such as construction, transportation, medical, and packaging have benefitted

89 from the mechanical characteristics of clay-reinforced polymeric nanocomposites and their

90 improved functional properties (e.g. ablation performance, fire retardancy, and gas permeability).

91 The literature shows that introducing nanoparticles into a PTFE matrix can enhance the tribological

92 properties of PTFE-based composites. However, adding these nanoparticles increases the final cost

93 of the product, and improvements in both the mechanical and functional performance of the

94 various polymeric systems are dependent on the degree of clay dispersion in the polymeric matrix

$95[29,30]$. The benefit of CNSs is that they have competitive cost and superior characteristics that

96 improve the mechanical behaviour of the host polymers [30-32]. CNSs also benefit from having

97 a 2D structure [33-37], in comparison to other nanoparticles (e.g. $\mathrm{Al}_{2} \mathrm{O}_{3}$ or $\mathrm{ZnO}$ ).

98 In this study, functionalized clay nano-sheets with organic modifiers were used to allow the

99 required miscibility within the polymer and better incorporation/exfoliation. The effects of adding

100 CNSs on the wear resistance, friction coefficient, and wear mechanism of PTFE-based

101 nanocomposites in a dry environment were investigated. It should be noted that embedding CNSs

102 within a polymer matrix produces a dense composite with high consistency, while also affecting

103 the polymer crystallisation behaviour. Furthermore, intermediate phases may be developed

104 because of the CNSs in the polymer matrix, possibly affecting the mechanical characteristics of

105 the manufactured nanocomposites [30, 38]. It has been reported that polymeric nanocomposite

106 coatings containing 5\% CNSs have a homogenous structure with no cracks [39]. 
107 A literature review showed that there has been limited research on the enhancement of the

108 mechanical characteristics and evaluation of the physical behaviour of CNSs/polymer

109 nanocomposites. Additionally, there are no reports of mechanical and tribological studies of two-

110 dimensional CNS-reinforced ring-shaped bulk PTFE composites. In this work, CNS/PTFE

111 samples were prepared by a compression moulding method and subsequent sintering processes.

112 The dispersion of CNSs in the polymeric matrix, wear resistance, friction coefficient, and its

113 mechanisms were studied by conducting XRD, EDX, and pin-on-ring measurements as well as

114 optical and scanning electron microscopies.

\section{2. Experimental Procedure}

\section{2.1. Materials and Processing}

117 Commercially available polytetrafluoroethylene powder (Dyneon ${ }^{\mathrm{TM}}$ PTFE, Dyneon LLC, USA) 118 with an average grain size of $550 \mu \mathrm{m}$ and modified nano-clay sheets (Cloisite 30B, Southern Clay 119 Co. USA) with an average grain size of $200 \mathrm{~nm}$ were used as the starting materials. Cloisite 30B 120 is a type of Cloisite $\mathrm{Na}^{+}$that, according to the manufacturer specifications, has been organically

121 modified via an ion-exchange reaction with a quaternary ammonium salt. Methyl tallow bis-2-

122 hydroxyethyl ammonium cations are the organic modifier of Cloisite 30B, at a loading of 90 $123 \mathrm{meq} / 100 \mathrm{~g}$ clay, and the tallow is $\sim 65 \% \mathrm{C}_{18}, \sim 30 \% \mathrm{C}_{16}$ and $\sim 5 \% \mathrm{C}_{14}$ (Fig. 1). The goal of the 124 current work was to develop composites with an appropriate CNS distribution in the PTFE matrix 125 to enhance the density of the as-sintered samples. Fig. 1 shows a schematic of the experimental 126 process.

127 To evaluate the influence of CNSs on the anti-abrasive characteristics of the PTFE-based 128 composites, CNSs were added to the PTFE matrix at various contents (1, 3, and 5 wt. \%). 
129 Additionally, a pure PTFE specimen was fabricated without any CNS added. To prepare the

$130 \mathrm{CNS} / \mathrm{PTFE}$ composites at the predefined compositions, firstly, CNSs were ultra-sonicated for $\sim 20$

$131 \mathrm{~min}$ in an acetone medium to de-agglomerate them. Subsequently, PTFE powder was added and

132 the dispersion process continued for an additional $30 \mathrm{~min}$. Second, acetone was removed from the

133 mixture by heating the slurry on a hotplate magnetic stirrer at $80{ }^{\circ} \mathrm{C}$ for $30 \mathrm{~min}$. Third, the samples

134 were compressed using a hydraulic press machine at $50 \mathrm{MPa}$ for $15 \mathrm{~min}$. Finally, a sintering

135 procedure was performed using a tubular furnace because of the high-temperature reactivity of

136 fluorine-ethylene in the PTFE matrix. An inert gas (argon) flowed through the furnace during the

137 sintering process. The samples were sintered for $3 \mathrm{~h}$ at a controlled heating/cooling rate and a

138 dwelling time at the maximum temperature of $350^{\circ} \mathrm{C}$. Pure PTFE samples (without CNSs) were

139 also prepared following the same procedure, for comparison purposes. Samples were heated from

140 room temperature to $300{ }^{\circ} \mathrm{C}$ at a rate of $55^{\circ} \mathrm{C} / \mathrm{h}$ and held at $300{ }^{\circ} \mathrm{C}$ for $90 \mathrm{~min}$. Subsequently, the

141 samples were heated from 300 to $350{ }^{\circ} \mathrm{C}$ at a rate of $23{ }^{\circ} \mathrm{C} / \mathrm{h}$ and held at the sintering temperature

$142\left(350{ }^{\circ} \mathrm{C}\right)$ for $3 \mathrm{~h}$. Samples were then cooled from 350 to $320^{\circ} \mathrm{C}$ at a rate of $-9^{\circ} \mathrm{C} / \mathrm{h}$, followed by

143 cooling from 320 to $300{ }^{\circ} \mathrm{C}$ at $-10{ }^{\circ} \mathrm{C} / \mathrm{h}$. The process was completed by cooling from $300{ }^{\circ} \mathrm{C}$ to

144 room temperature at a rate of $-55^{\circ} \mathrm{C} / \mathrm{h}$. Ring-shaped samples with an inner diameter of $24.7 \mathrm{~mm}$

145 and an outer diameter of $30.7 \mathrm{~mm}$ were finally obtained.

\subsection{Characterisation}

149 X-ray diffraction patterns (XRD, D5000, Siemens Co., Germany) at $40 \mathrm{kV}, 60 \mathrm{~mA}, 1500 \mathrm{~W}$, with $150 \mathrm{Cu}-\mathrm{K} \alpha(\mathrm{k}=0.154 \mathrm{~nm})$ at $2 \theta$ angles from 0 to $40^{\circ}$ were assessed. The goal of the current study was 
151 to prepare composites with an appropriate CNS distribution in the PTFE matrix and produce dense

152 composites with high consistency. Therefore, to verify the uniform distribution of CNSs in the

153 polymeric matrix, energy-dispersive X-ray spectroscopy (EDX, attached to a scanning electron

154 microscope (FE-SEM, MIRA3, Tescan Co., Brno, Czech Republic)) and XRD data were used for 155 qualitative elemental analysis.

156 To evaluate the mechanical properties of the manufactured samples, a tensile test (Zwick Roell

157 Z010, USA) was conducted in accordance with the ASTM 638 standard, with a load rate of 50

$158 \mathrm{~mm} / \mathrm{min}$ at ambient temperature. To calculate abrasion resistance, a pin-on-ring wear test was

159 conducted on the specimens at $25{ }^{\circ} \mathrm{C}$ at a relative humidity of $25-35 \%$. The pin surface was made

160 of SAE 304 stainless steel with a surface roughness of $0.1 \mu \mathrm{m} \mathrm{Ra}$. After each test, any adhered

161 material was removed from the surface of the pin using sandpaper. The surfaces of the samples

162 were thoroughly cleaned before the measurement to avoid any bias in the evaluation of wear

163 behaviour. For all tests, the contact pressure on the pin was $1.13 \mathrm{MPa}$, the pin speed was $60 \mathrm{~mm} / \mathrm{s}$,

164 and the wear length for the pure PTFE and samples containing 1,3, and $5 \mathrm{wt} . \%$ was $1000 \mathrm{~m}$. After

165 each test, samples were weighed to ascertain the mass of the removed material. The topography of

166 the samples after the wear and tensile tests was also studied. The fragments obtained from each

167 test during the wear evaluation were also gathered for further study.

168 Surface observation and assessment of the samples, prior to and after evaluations, were carried out

169 using a scanning electron microscope (SEM, VEGA TESCAN, Czech Republic). A gold sputtering

170 apparatus (Emitech K550, Kent, UK) was used to coat the samples with a thin gold layer before

171 the SEM assessment. Additionally, the formation of a transition film on the opposing surfaces was

172 investigated using an optical microscope (Nikon Eclipse ME 600, Japan). All reported data in this

173 study are the average of three measurements. 


\section{Results and Discussion}

177 It has been frequently reported that controlling the distribution and uniformity of the secondary 178 phases in filler-reinforced PTFE composites is difficult because of the absence of in-situ 179 polymerisation and fusion processes. To resolve this in the current work, a two-step mixing method

180 was used to break down/exfoliate any possible agglomerations of CNSs and fully disperse them in

181 the PTFE matrix. To ensure that the CNSs were not agglomerated and the sheets were exfoliated 182 appropriately as well as to investigate the distribution of CNSs in the PTFE matrix, EDX and XRD 183 analyses were used (Fig. 2). Five samples, including pure CNSs without treatment, pure PTFE, 184 and the composite specimens containing 1, 3, and 5 wt.\% CNSs, were studied.

186 As shown in the XRD results (Fig. 2a), the pure CNSs showed a characteristic peak at $2 \theta=4.8^{\circ}$.

187 This was used to measure the sheet distance in the CNSs for use in the Bragg equation $188\left(\mathrm{n} \lambda=2 \mathrm{~d}_{(\mathrm{hkl})} \operatorname{Sin} \theta\right)$, and $\mathrm{d}_{(\mathrm{hkl})}$ was calculated to be $18.5 \AA$. Additionally, a strong peak at $2 \theta=18^{\circ}$

189 corresponds to the characteristic peak of PTFE. The XRD patterns of the sintered composites 190 revealed no peaks for CNSs; the characteristic peak of PTFE was dominant in all samples. The 191 absence of the characteristic peak of CNSs in the XRD patterns of the nanocomposites indicates 192 destruction of the layered structure and exfoliation of the clay in the PTFE matrix. However, a low 193 level of roughness was observed on the surface of the sample containing $5 \mathrm{wt} \%$ clay (Fig. 2c) as 194 well as the existence of some lumps in Fig. 4. This implies that a highly exfoliated state was 195 achieved, while a small proportion of the clays was intercalated owing to the clay concentration. 
196 This has also been observed for the dispersion of CNSs in high-density polyethylene [40] and some

197 other polymeric composites [41-44].

198 Considering the EDX spectrum and the chemical formula of PTFE $\left(\mathrm{C}_{2} \mathrm{~F}_{4}\right)_{\mathrm{n}}$, the detection of carbon

199 (C) and fluorine (F) elements can be ascribed to the presence of PTFE. Furthermore, because CNSs

200 are mainly made of silica layers, the peak for the silicon ( $\mathrm{Si}$ ) element indicates the presence of

201 CNSs in the sample (Fig. 2b). Taking this fact into account, a normalising process based on these

202 three elements (i.e. C, F, and $\mathrm{Si}$ ) was used to calculate their weight percentage, but this does not

203 represent the exact weight percentage of the analysed elements in the prepared sample.

204 Consequently, these elements can be qualitatively detected in the sample, and the uniform

205 distribution of CNSs in the sample can be seen in Fig. 2c. The results were further confirmed by

206 SEM observations.

207 Individual layers of CNSs were not found in the SEM images (Figs. 2c, 4, and 8). The absence of 208 these layers in a broad range of the investigated samples suggests that the CNSs were 209 dispersed/exfoliated adequately. The dispersing method used in this study was therefore able to

210 break down and exfoliate the agglomerations of CNSs and led to effective distribution of CNSs in

211 the PTFE matrix. Regarding the manufacture of PTFE-based nanocomposites, the second phase

212 distribution has a significant role in the tribological characteristics of the prepared material. As a

213 result of the appropriate dispersion of CNSs in the PTFE matrix, the mechanical characteristics of

214 the prepared composites in this work are in good agreement with previously published studies on

215 the properties of PTFE nanocomposites [21, 25, 34, 40].

$216 \quad 3.2$ Tensile properties

217 To investigate the effect of CNSs on the tensile behaviour of the PTFE-based composites, various 
218 samples, including pure PTFE and CNS/PTFE nanocomposites, were studied (Fig. 3). Fig. 3a

219 shows the stress-strain curves of the prepared samples. Figs. 3b-d illustrate the effect of adding

220 CNSs on the elastic modulus, ultimate tensile strength (UTS), and strain at UTS, respectively.

223 It can be inferred from Fig. 3a that the strength of the samples decreases in the plastic region as

224 the CNC content increases. In the curve for the pure PTFE, the strength continuously increases

225 because of the strain-hardening phenomenon until the UTS is reached. However, after the UTS, 226 the pure sample shows a necking tendency before fracture. No evidence of the necking 227 phenomenon in the CNS-reinforced PTFE samples is observed. The presence of CNSs reduces the 228 elongation of the samples, and the fracture mode tends to be more brittle. As is evident in Figs.

$2293 \mathrm{~b}-\mathrm{d}$, adding CNSs decreases the fracture strength of the samples. The most probable reason for 230 this is a weak interaction between the CNSs and the PTFE matrix, which also reduces the tensile 231 strength of the samples.

232 It is also observed that adding CNSs considerably increases the elastic modulus. Furthermore, a 233 direct relationship between the CNS content and the elastic modulus of the samples was found.

234 This can be explained by the following reasons. First, CNSs have a greater modulus (4.657 GPa) 235 [45] than the PTFE matrix (3.9 GPa), so the addition of CNSs can improve the elastic modulus. 236 Secondly, CNSs can restrain the movement of polymer molecular chains. This is because the fully 237 exfoliated CNSs can be appropriately incorporated within the polymer matrix and enhance their 238 interactions with the polymer, minimising chain mobility and creating reinforcement effects [29, $23946,47]$. Finally, CNSs can resist plastic strain and subsequently cause an increase in the slope of 240 the stress-strain curve in the elastic region, as observed here and reported in the literature [40, 45]. 
242 SEM images of the fractured surfaces of the samples after the tensile test are presented in Fig. 4.

243 In Fig. 4a, it is evident that the fractured surface of the pure PTFE shows slip lines (i.e. a micro-

244 ductile fracture mode) with the formation of small pits or micro-craters. The observed fibrous

245 structure in Fig. 4 could be related to the ductility and cohesive fracture of the prepared samples

246 (shown in Fig. 3), because of the high elongation characteristics of pure PTFE.

248 The slip lines in Figs. 4b-d do not occur in the vicinity of the CNSs and weak interfaces between

249 the CNSs and the PTFE matrix. This could be related to the nonpolar characteristics and low

250 energy level of PTFE. Because of these conditions, CNSs are simply separated from the

251 surrounding PTFE matrix. Conversely, the interfaces of CNSs and PTFE could act as stress

252 concentration regions for microcrack initiation. Such micro-cracks would connect as the load

253 increases, ultimately leading to sample failure. In summary, CNSs interrupt the cohesion of PTFE

254 molecules; hence, they cannot endure applied force as well as the pure PTFE. As shown in Fig.

$2554 \mathrm{~d}$, the number of slip lines is considerably reduced, verifying that a relatively brittle fracture is 256 dominant in the sample containing 5 wt. \% CNSs.

257 As mentioned previously, controlling the uniformity and distribution of CNSs in the PTFE matrix

258 is difficult because of the absence of fusion processes and in-situ polymerisation. Hence, other

259 procedures should be employed to disperse an additive in the PTFE matrix. Because of a lack of

260 uniformity when dispersing fillers in a PTFE matrix, they are sometimes agglomerated around the

261 PTFE powder. In all PTFE-based composites, the distribution and uniformity of the embedded

262 fillers are linked to the grain size of the employed PTFE powder. 
263 To overcome this problem, (i.e. the inherent difficulty of uniformly distributing fillers and the

264 difficulty of mixing CNSs into the PTFE matrix), modified CNSs were used and mixed through

265 several steps (Fig. 1) to disperse CNSs into the PTFE. However, lumps that were detected

266 (represented by circles) in Fig. 4 and the probability of these lumps occurring in other samples

267 could be related to the accumulation of CNSs on the surface of the PTFE powder. The grain size

268 of the PTFE used in the current work is approximately $550 \mu \mathrm{m}$, and the embedded CNSs have a

269 size of approximately $200 \mathrm{~nm}$. As the grain size of PTFE powder is $2.75 \times 10^{3}$ times larger than that

270 of the CNSs, the PTFE powder could be surrounded by CNSs during the mixing and preparation

271 of the nanocomposites. Consequently, the agglomeration of CNSs around the PTFE grains could

272 decrease the binding force between the grains of the matrix and lead to a reduction in the

273 homogeneity of the prepared nanocomposites. This is in addition to having adverse effects on their

274 mechanical characteristics, as shown in Fig. 3. In the worst case, CNSs agglomerate around the

275 PTFE powder and the developed composites behave as microcomposites; however, the data from

276 the present study show good conformity with previously published works regarding PTFE-based

277 nanocomposites [11, 15, 18, 19, 21, 25-27, 34, 40, 48, 49] (Table 1). Sawyer et al. [26] showed

278 that matrix PTFE particles were much larger than embedded $\mathrm{Al}_{2} \mathrm{O}_{3}$ nanoparticles after

279 compression moulding. They indicated that the resulting structure was probably cellular, with

280 PTFE islands surrounded by a continuous casing of $\mathrm{Al}_{2} \mathrm{O}_{3}$ rich composite material. The

281 enhancement in the wear resistance resulting from this casing material interrupts the wear process 282 of the PTFE.

283 3.4 Tribological characteristics

284 To assess the tribological characteristics of the prepared nanocomposites and pure PTFE samples, 285 abrasion evaluations were conducted. Data for the friction coefficient versus wear distance in the 
CNS/PTFE composites at various contents of CNSs are provided in Fig. 5. The average value of

287 the friction coefficient was calculated according to Eq. 1.

$$
\bar{\mu}=\frac{1}{t} \int_{0}^{t} \mu d t
$$

289 where $t$ represents the total time of the test. The average friction coefficients for specimens 290 containing $0,1,3$, and 5 wt. \% CNSs were calculated to be $0.127,0.057,0.066$, and 0.071 291 respectively.

293 The pin-on-ring friction measurement system used in this study includes one brittle material 294 (stainless-steel pin) and one soft material (PTFE). Although both friction mechanisms are always 295 active (i.e. adhesion and ploughing), the dominant friction mechanism is ploughing [50]. In the 296 ploughing mechanism, the shear strength of the soft material dictates the friction rate of the system. 297 When CNSs are added to PTFE, the number of defects and weak interfaces between CNSs and the 298 PTFE matrix increases, decreasing the shear strength of the material. This fact is also evident in 299 Fig. 3, which shows a reduction in the mechanical strength of the PTFE-based composites after 300 incorporating the CNSs. This means that adding CNSs reduces the mechanical strength of the 301 PTFE, resulting in a reduced friction coefficient, as shown in Fig. 5.

302 In the composite samples with 1 and 3 wt. \% CNSs, the friction coefficients were approximately 303 half of that of the pure PTFE. However, increasing the CNS content up to 5\% showed a negligible 304 increase in the friction coefficient. According to the curve for $5 \mathrm{wt}$ \% $\%$ CNSs, the friction coefficient 305 remained almost constant until $1000 \mathrm{~m}$ abrasion. One reason for this phenomenon could be related 306 to the erosion of some CNSs and their presence between the two sliding surfaces (i.e. the pin and 
307 the sample). Additionally, this phenomenon could be explained by a change in the surface

308 roughness. A fracture could liberate some CNSs, which would increase the surface roughness of 309 the parent surfaces and lead to an increase in adhesive friction [50]. This is evident in Fig. 5 for 5

310 wt. \% CNSs. However, as discussed, the contribution of the adhesive friction mechanism was not

311 significant for the system containing the stainless-steel pin and PTFE composites. Therefore, its

312 effect on the friction coefficient was negligible.

313 In Fig. 6, the temperature variation as a function of wear distance in the CNS/PTFE composites is 314 presented.

316 As shown in Fig. 6, by increasing the distance travelled, the temperature between the sliding 317 surfaces increases owing to heat produced by the friction. The measurements show that the 318 temperature increases up to $80{ }^{\circ} \mathrm{C}$ in the sample containing 5 wt. \% CNSs. For abrasion distances 319 up to $\sim 1000 \mathrm{~m}$, the slope of the temperature-distance curve in the CNS/PTFE composites is lower 320 than that of the pure PTFE. The main reason for this behaviour may be linked to the reduction in 321 friction imparted by the CNSs (Fig. 5). For the samples containing CNSs, the friction coefficients 322 were initially raised due to the presence of the filler at the surface and then reduced, potentially 323 due to the formation of a transition film.

324 Eq. 2 was used to calculate the special wear rates $\left(W_{S}\right)$ of the samples during the abrasion test.

$$
W_{s}=\frac{\Delta m}{F L \rho}
$$

326 where $W_{S}$ is the special wear rate $\left(\mathrm{mm}^{3} / \mathrm{Nm}\right), \Delta m$ is the mass loss within the wear test $(\mathrm{g}), L$ 327 represents the wear distance $(\mathrm{m}), F$ is the vertical force applied to the specimen $(\mathrm{N})$, and $\rho$ is the 
328 density of the sample $\left(\mathrm{g} / \mathrm{mm}^{3}\right)$.

329 The special wear rates for the specimens containing $0,1,3$, and 5 wt. $\%$ CNSs were $1.09 \times 10^{-3} \pm$

$3301.07 \times 10^{-5}, 0.19 \times 10^{-3} \pm 1.02 \times 10^{-5}, 3.59 \times 10^{-5} \pm 1.15 \times 10^{-6}$, and $0.32 \times 10^{-5} \pm 2.32 \times 10^{-7}$, respectively.

331 It can be concluded that adding CNSs significantly reduces the wear rate. In a comparison with

332 the wear rate of pure PTFE, it was revealed that adding CNSs to PTFE causes a wear resistance

333 improvement of approximately six times for the sample containing $1 \mathrm{wt}$ \% CNSs. For the samples

334 with 3 and 5 wt. \% CNSs, the improvements in abrasion properties are $\sim 30$ and $\sim 340$ times,

335 respectively.

336 The tribological performances of all PTFE composites could be influenced by the following three 337 issues:

(I) the mechanical and geometrical conditions of the slip interfaces between the sample and pin,

(II) the mechanical characteristics of the matrix,

(III) the characteristics of the transition film, as discussed further in the following section.

342 Table 1 presents a comparison of the wear resistance of the nanocomposite in the current study (5

343 wt. \% CNSs-PTFE) with other studies. The effect of the filler content, size, and type of the

344 embedded nanoparticles is assessed.

Table 1: Comparison of abrasion test results of PTFE-based nanocomposites

\begin{tabular}{|c|c|c|c|c|c|}
\hline Type of additives & $\begin{array}{c}\text { Size of } \\
\text { additives }(\mathrm{nm})\end{array}$ & $\begin{array}{c}\text { Additive } \\
\text { content }(\%)\end{array}$ & $\begin{array}{l}\text { Wear rate } \\
\left(\mathrm{mm}^{3} / \mathrm{Nm}\right)\end{array}$ & Test medium & Ref. \\
\hline Clay nano-sheets & 200 & 5 & $0.32 \times 10^{-5}$ & dry & Current work \\
\hline $\mathrm{Al}_{2} \mathrm{O}_{3}$ & 40 & 6 & $3.00 \times 10^{-5}$ & dry & {$[26]$} \\
\hline $\mathrm{Al}_{2} \mathrm{O}_{3}$ & 40 & 5 & $29.4 \times 10^{-5}$ & dry & [49] \\
\hline $\mathrm{ZnO}$ & 80 & 6 & $1.30 \times 10^{-5}$ & dry & {$[25]$} \\
\hline $\mathrm{SiO}_{2}$ nanospheres & 60 & 5 & $2.50 \times 10^{-5}$ & dry & [11] \\
\hline $\mathrm{ZrO}_{2}$ & 20 & 8 & $0.37 \times 10^{-5}$ & dry & {$[18]$} \\
\hline $\begin{array}{c}\text { single-walled carbon } \\
\text { nanotubes }\end{array}$ & 2 & 5 & $3.10 \times 10^{-5}$ & dry & {$[27]$} \\
\hline
\end{tabular}




\begin{tabular}{ccclcc} 
Expanded graphite & - & 5 & $0.23 \times 10^{-5}$ & dry & {$[48]$} \\
$\mathrm{Ag}_{2} \mathrm{~S}$ & $25-40$ & 15 & $5.60 \times 10^{-5}$ & dry & {$[19]$} \\
$\mathrm{SiC}$ & 500 & 15 & $14.0 \times 10^{-5}$ & deionized water & {$[15]$} \\
$\mathrm{Si}_{3} \mathrm{~N}_{4}$ & 500 & 15 & $46.0 \times 10^{-5}$ & (DW) & {$[11]$} \\
$\mathrm{SiO}_{2}$ & 500 & 15 & $31.0 \times 10^{-5}$ & DW & {$[11]$} \\
\hline
\end{tabular}

347 As can be seen in Table 1, the effect of adding CNSs in the current study is comparable to that of 348 other studies in the literature, considering the content and its particle size. In addition, the size and 349 amount of the fillers, filler type, and their geometric shape can also affect the tribological 350 characteristics of the prepared nanocomposites. Consequently, CNSs as a 2D material with high 351 availability and competitive costs can effectively enhance the tribological performance of PTFE352 based nanocomposites.

353 An elemental distribution assessment was conducted on the sample containing 5 wt. \% CNSs (Fig. 354 7).

356 From the EDX data, the percentage distributions of the elements $\mathrm{Si}, \mathrm{C}$, and F were measured to be $3575.3 \%, 31.8 \%$, and $54.7 \%$, respectively. It is shown that the percentage content of Si increased 358 following the wear test (Fig. 2b). Consequently, it can be concluded that the CNSs were eroded 359 less in comparison with the PTFE matrix during the wear test.

$360 \quad 3.5$ SEM investigations after tribological tests

361 To investigate the effects of CNSs on the tribological characteristics of the PTFE nanocomposites 362 and to study the wear mechanisms, the topography of the prepared samples after abrasion tests was 363 studied by SEM (Fig. 8). Additionally, the transition film formation on the opposing surfaces was 364 studied using an optical microscope (Fig. 9). 
366 The wear mechanism of the samples could be different based on the abrasive environment. Among 367 various wear mechanisms, abrasive and adhesive mechanisms are dominant. These two 368 mechanisms are more relevant for the condition of this study due to the abrasion effects of two 369 objects and poor interaction of PTFE with other materials.

370 Fig. 8a shows the surface of the pure PTFE specimen, where the direction of sliding was from left

371 to right (the erosion pattern of the steel pin is clear). As the wear surface is smooth and uniform, 372 the wear mechanism of the pure PTFE is predominantly an adhesive one. Fig. 8b shows the surface 373 of the 1 wt. \% CNS-reinforced PTFE sample where, in comparison to the pure PTFE, some 374 disruption and cracks (represented by arrows) can be seen. Additionally, CNSs tend to be cut from 375 the surface as the $\mathrm{CNC}$ content increases (indicated by circles), clearly signalling a shift of the 376 wear mechanism from adhesive to abrasive.

377 In the pure PTFE samples, only two materials (PTFE as the test sample and the 304 stainless-steel 378 pin) are present in the sliding system. However, in the composite PTFE, CNS particles are trapped 379 between the rubbing surfaces. Due to the hardness of the CNS swarf, scratches are caused on the 380 PTFE material (the trace of this phenomenon is indicated by the arrows in Fig. $8 \mathrm{c}$ and d). This 381 causes the wear mechanism to change from adhesive to abrasive. Uneven surfaces are observed, 382 with numerous cracks and disruptions (ridges and grooves) in the samples with $3 \%$ and 5 wt. $\%$ 383 CNSs (Figs. 8c and d). It can be concluded that by increasing the content of CNSs, the wear 384 mechanism changes from an adhesive type (cutting of thin sheets) to an abrasive one. In the 385 samples with 5 wt.\% CNSs the dominant wear mechanism has three-component abrasive wear. 386 The production of swarf in the nanocomposite is due to the abrasive characteristics of the cut 387 CNSs. Furthermore, it can be seen that the swarf produced between the pure PTFE and the sliding 
388 pin surface is composed of very thin sheets with relatively coarse dimensions when compared to

389 the swarf from the 5 wt.\% CNSs-PTFE nanocomposite (Figs. 9a and b).

390 It has been shown that when polymers are modified by adding various fillers, transfer film 391 formation can affect their tribological behaviour. Some fillers affect the development of the 392 transfer film and enhance its adhesion to the counterface. Such fillers reduce the wear rate of the 393 polymer, often dramatically [51]. The results of the friction and wear behaviour for embedded 394 CNSs are discussed in view of the transfer film characteristics in the current study. CNSs, as hard 395 minerals with a desirable wear resistance compared to the PTFE matrix, could increase the wear 396 resistance of the final nanocomposites.

397 Transition film formation is directly affected by the formation of swarf. In the case of pure PTFE, 398 because of the geometrical shape and size of these fragments, they cannot locate themselves 399 adjacent to other fragments to create a uniform layer (transition film). The formed fragments are 400 cut and piled up around the contact interfaces, preventing full formation of a transition film and 401 causing the abrasive pin to be in constant contact with the sample surface. This is observed on the 402 abrasive surface shown in Fig 9c.

404 Transition film formation and its characteristics are among the crucial parameters in decreasing 405 the wear rate of various engineering components, particularly under dry abrasion conditions. 406 Images of the fragments formed after surface erosion and the formed transition layers for the 407 nanocomposite containing 5 wt. \% CNSs are shown in Figs. 8 and 9. It is clear that the erosion 408 surface is somewhat interconnected and uniform (Fig. 8d). Additionally, Fig. 8d shows that the 409 obtained fragments are cut by a slip mechanism (unlike the anchoring mechanism, which occurs 
410 in the pure PTFE samples). Consequently, it can be stated that the abrasion behaviour of the

411 manufactured pure PTFE and composites is not similar. The first reason for the change in the

412 abrasion mechanism of pure PTFE and its nanocomposites can be due to transition film formation.

413 Unlike pure PTFE, a uniform transition layer can be formed in the samples containing 5 wt. \%

414 CNSs (Fig. 9d). This uniform and continuous transition film covers the surface of the abrasive pin.

415 Hence, in these samples, the surface of the composite is not constantly in contact with the abrasive

416 pin. However, to investigate transfer films in more detail, X-ray photoelectron spectroscopy (XPS)

417 is suggested, as a further study.

418 Evaluation of the formed fragments in the reinforced samples after the wear test shows that they

419 remained in position, potentially progressing to form a single layer. Considering the morphology

420 of the investigated nanocomposites, it can be stated that by increasing the filler content, the surface

421 of the samples was more interconnected and uniform after the wear test. Based on these

422 observations, in the CNS/PTFE composites, the wear mechanism is of the adhesive type; however,

423 the abrasive mechanism occurs because of clinging between a formed transition film and the

424 sample surface.

\section{4. Conclusions}

426 Experimental investigations were performed to evaluate the effects of adding clay nano-sheets on

427 the mechanical properties of PTFE. PTFE composites with 1, 3, and $5 \mathrm{wt} \%$ CNSs as well as pure

428 PTFE samples were prepared. The characteristic peaks of CNSs were not detected by XRD

429 analysis of the composite samples, and individual layers of CNSs were not found in the SEM

430 images, demonstrating that the methodology used to create the composites fully dispersed the

431 CNSs into the PTFE. 
432 Tensile results showed that adding CNSs to PTFE decreased the UTS and strain at UTS because

433 of weak bonding between the PTFE and CNSs. Topographical studies of the tested specimens

434 using SEM indicated that the interfaces of CNSs and PTFE could act as stress concentration

435 regions for microcrack initiation, decreasing the tensile strength. Increasing the CNC content in

436 the PTFE also reduced its ductility. However, the presence of CNSs improved the elastic modulus.

437 This could be attributed to the capability of CNSs to restrict the slip of the molecular chains of

438 PTFE in the composite.

439 Wear tests revealed that adding CNSs up to a specific value (5 wt. \%) reduced the friction

440 coefficient. The main reason for this phenomenon was a reduction in the real contact area between

441 the sliding surfaces. SEM and optical microscopy investigations showed that the dominant wear

442 mechanism in the pure PTFE was adhesive, which changed to abrasion with the addition of CNSs.

443 This change could be attributed to the formation of a uniform transition film. This enhanced the

444 wear resistance of the CNS/PTFE nanocomposites. Among the test samples used in this study, 5

445 wt. \% CNS-reinforced PTFE composite showed the best wear resistance, with an improvement of

446340 times that of pure PTFE.

References

449 [1] J. Zhang, J. Liu, Z. Wang, W. Chen, B. Hu, Y. Zhang, H. Liao, S. Ma, Tribological behavior 450 and lubricating mechanism of Si3N4 in artificial seawater, Ceramics International, 46 (2020) 451 14361-14368.

452 [2] H. Ruan, Q. Zhang, W. Liao, Y. Li, X. Huang, X. Xu, S. Lu, Enhancing tribological, 453 mechanical, and thermal properties of polyimide composites by the synergistic effect between 454 graphene and ionic liquid, Materials \& Design, 189 (2020) 108527.

455 [3] K. Holmberg, A. Erdemir, Influence of tribology on global energy consumption, costs and 456 emissions, Friction, 5 (2017) 263-284.

457 [4] J. Joseph, P.R. Munda, M. Kumar, A.M. Sidpara, J. Paul, Sustainable conducting polymer 458 composites: study of mechanical and tribological properties of natural fiber reinforced PVA 
composites with carbon nanofillers, Polymer-Plastics Technology and Materials, (2020) 1-12. [5] A. Roy, L. Mu, Y. Shi, Tribological properties of polyimide-graphene composite coatings at elevated temperatures, Progress in Organic Coatings, 142 (2020) 105602. [6] Y. Yang, H. Wang, J. Ren, G. Gao, S. Chen, N. Wang, G. Zhao, J. Wang, Core-shell polytetrafluoroethylene@ @ phenolic resin composites: Structure and tribological behaviors, Tribology International, 144 (2020) 106092. [7] X. Wu, W. Li, K. Chen, D. Zhang, L. Xu, X. Yang, A tough PVA/HA/COL composite hydrogel with simple process and excellent mechanical properties, Materials Today Communications, 21 (2019) 100702.

[8] S.M. George, B. Kandasubramanian, Advancements in MXene-Polymer composites for various biomedical applications, Ceramics International, 46 (2020) 8522-8535.

[9] S. Li, S.-Q. Zhang, L. Shen, Q. Liu, J.-B. Ma, W. Lv, Y.-B. He, Q.-H. Yang, Progress and Perspective of Ceramic/Polymer Composite Solid Electrolytes for Lithium Batteries, Advanced Science, 7 (2020) 1903088.

[10] A. McIlhagger, E. Archer, R. McIlhagger, 3 - Manufacturing processes for composite materials and components for aerospace applications, in: P. Irving, C. Soutis (Eds.) Polymer Composites in the Aerospace Industry (Second Edition), Woodhead Publishing2020, pp. 59-81. [11] G. Shi, Q. Wang, T. Sun, X. Yan, In situ filling of SiO2 nanospheres into PTFE by sol-gel as a highly wear-resistant nanocomposite, Journal of Applied Polymer Science, 137 (2020) 49096.

[12] C.A. Sperati, H.W. Starkweather, Fluorine-containing polymers. II. Polytetrafluoroethylene, Fortschritte Der Hochpolymeren-Forschung, Springer Berlin Heidelberg, Berlin, Heidelberg, 1961, pp. 465-495.

[13] W.E. Hanford, R.M. Joyce, Polytetrafluoroethylene, Journal of the American Chemical Society, 68 (1946) 2082-2085.

[14] B. Cheng, K. Ishihara, Formation of stable polydopamine layer on polytetrafluoroethylene substrate by hybrid process involved plasma treatment and spontaneous chemical reactions, Materials Today Communications, 22 (2020) 100774.

[15] B. Lin, A. Wang, T. Sui, C. Wei, J. Wei, S. Yan, Friction and wear resistance of polytetrafluoroethylene-based composites reinforced with ceramic particles under aqueous environment, Surface Topography: Metrology and Properties, 8 (2020) 015006.

[16] H. Wang, F. Zhou, J. Guo, H. Yang, J. Tong, Q. Zhang, Modified BCZN particles filled PTFE composites with high dielectric constant and low loss for microwave substrate applications, Ceramics International, 46 (2020) 7531-7540.

[17] M. Lv, L. Wang, J. Liu, F. Kong, A. Ling, T. Wang, Q. Wang, Surface energy, hardness, and tribological properties of carbon-fiber/polytetrafluoroethylene composites modified by proton irradiation, Tribology International, 132 (2019) 237-243.

[18] G. Gao, J. Gong, Y. Qi, J. Ren, H. Wang, D. Yang, S. Chen, Tribological Behavior of PTFE Composites Filled with PEEK and Nano-ZrO2, Tribology Transactions, 63 (2020) 296-304.

[19] Y. Ma, H. Wan, Y. Ye, L. Chen, H. Li, H. Zhou, J. Chen, In-situ synthesis of size-tunable silver sulfide nanoparticles to improve tribological properties of the polytetrafluoroethylene-based nanocomposite lubricating coatings, Tribology International, 148 (2020) 106324.

[20] M. Qu, Y. Yao, J. He, X. Ma, J. Feng, S. Liu, L. Hou, X. Liu, Tribological study of polytetrafluoroethylene lubricant additives filled with $\mathrm{Cu}$ microparticles or $\mathrm{SiO} 2$ nanoparticles, Tribology International, 110 (2017) 57-65.

504 Wear Resistance of Alumina-Filled PTFE Micro- and Nanocomposites, Tribology Transactions, 
51 (2008) 247-253. [22] X. Cai, X. Dong, W. Lv, C. Ji, Z. Jiang, X. Zhang, T. Gao, K. Yue, X. Zhang, Synergistic enhancement of thermal conductivity for low dielectric constant boron nitridepolytetrafluoroethylene composites by adding small content of graphene nanosheets, Composites Communications, 17 (2020) 163-169.

[23] S. Yan, Y. Xue, Y. Hu, S. Wang, Thermal, mechanical, and tribological properties of sodiummontmorillonite-nanoparticle-reinforced polyethersulfone and polytetrafluoroethylene ternary composites, Friction, (2020).

[24] Y. Lv, W. Wang, G. Xie, J. Luo, Self-Lubricating PTFE-Based Composites with Black Phosphorus Nanosheets, Tribology Letters, 66 (2018) 61.

[25] F. Li, K.-a. Hu, J.-1. Li, B.-y. Zhao, The friction and wear characteristics of nanometer $\mathrm{ZnO}$ filled polytetrafluoroethylene, Wear, 249 (2001) 877-882.

[26] W.G. Sawyer, K.D. Freudenberg, P. Bhimaraj, L.S. Schadler, A study on the friction and wear behavior of PTFE filled with alumina nanoparticles, Wear, 254 (2003) 573-580.

[27] J.R. Vail, D.L. Burris, W.G. Sawyer, Multifunctionality of single-walled carbon nanotubepolytetrafluoroethylene nanocomposites, Wear, 267 (2009) 619-624.

[28] Y. Kojima, A. Usuki, M. Kawasumi, A. Okada, Y. Fukushima, T. Kurauchi, O. Kamigaito, Mechanical properties of nylon 6-clay hybrid, Journal of Materials Research, 8 (1993) 1185-1189. [29] A. Wagner, A.P. White, M.C. Tang, S. Agarwal, T.A. Stueckle, Y. Rojanasakul, R.K. Gupta, C.Z. Dinu, Incineration of Nanoclay Composites Leads to Byproducts with Reduced Cellular Reactivity, Scientific Reports, 8 (2018) 10709.

[30] R. Rafiee, R. Shahzadi, Predicting mechanical properties of nanoclay/polymer composites using stochastic approach, Composites Part B: Engineering, 152 (2018) 31-42.

[31] M.A. Msekh, N.H. Cuong, G. Zi, P. Areias, X. Zhuang, T. Rabczuk, Fracture properties prediction of clay/epoxy nanocomposites with interphase zones using a phase field model, Engineering Fracture Mechanics, 188 (2018) 287-299.

[32] M. Zamanian, M. Mortezaei, B. Salehnia, J.E. Jam, Fracture toughness of epoxy polymer modified with nanosilica particles: Particle size effect, Engineering Fracture Mechanics, 97 (2013) 193-206.

[33] D. Xiang, K. Li, W. Shu, Z. Xu, On the Tribological Properties of PTFE Filled with Alumina Nanoparticles and Graphite, Journal of Reinforced Plastics and Composites, 26 (2007) 331-339. [34] D.L. Burris, W.G. Sawyer, Improved wear resistance in alumina-PTFE nanocomposites with irregular shaped nanoparticles, Wear, 260 (2006) 915-918.

[35] F.-h. Su, Z.-z. Zhang, W.-m. Liu, Friction and wear behavior of hybrid glass/PTFE fabric composite reinforced with surface modified nanometer ZnO, Wear, 265 (2008) 311-318.

[36] L. Mu, J. Zhu, J. Fan, Z. Zhou, Y. Shi, X. Feng, H. Wang, X. Lu, Self-Lubricating Polytetrafluoroethylene/Polyimide Blends Reinforced with Zinc Oxide Nanoparticles, Journal of Nanomaterials, 2015 (2015) 545307.

[37] H. Dong, L. Wu, L. Zhang, H. Chen, C. Gao, Clay nanosheets as charged filler materials for high-performance and fouling-resistant thin film nanocomposite membranes, Journal of Membrane Science, 494 (2015) 92-103.

[38] P. Nguyen-Tri, T.A. Nguyen, P. Carriere, C. Ngo Xuan, Nanocomposite Coatings: Preparation, Characterization, Properties, and Applications, International Journal of Corrosion, 2018 (2018) 4749501.

[39] A. Golgoon, M. Aliofkhazraei, M. Toorani, M.H. Moradi, A.S. Rouhaghdam, Corrosion and Wear Properties of Nanoclay- polyester Nanocomposite Coatings Fabricated by Electrostatic 
Method, Procedia Materials Science, 11 (2015) 536-541.

552 [40] D. Cai, M. Song, Ultra-high enhancement in the toughness of polyethylene by exfoliated 553 natural clay nanosheets, Journal of Applied Polymer Science, 132 (2015).

554 [41] T. Lan, P.D. Kaviratna, T.J. Pinnavaia, Mechanism of clay tactoid exfoliation in epoxy-clay nanocomposites, Chemistry of Materials, 7 (1995) 2144-2150.

[42] H. Miyagawa, L.T. Drzal, J.A. Carsello, Intercalation and exfoliation of clay nanoplatelets in epoxy-based nanocomposites: TEM and XRD observations, Polymer Engineering \& Science, 46 (2006) 452-463.

[43] H. Xia, M. Song, Intercalation and exfoliation behaviour of clay layers in branched polyol and polyurethane/clay nanocomposites, Polymer International, 55 (2006) 229-235.

[44] J. Zhu, X. Wang, F. Tao, G. Xue, T. Chen, P. Sun, Q. Jin, D. Ding, Room temperature spontaneous exfoliation of organo-clay in liquid polybutadiene: Effect of polymer end-groups and the alkyl tail number of organic modifier, Polymer, 48 (2007) 7590-7597.

[45] W. Hao, L. Zhang, X. Wang, J. Wang, Z. Hu, W. Yang, Tough and strong nacre-like composites from hyperbranched poly(amido amine) and clay nanosheets cross-linked by genipin, RSC Advances, 6 (2016) 1415-1421.

[46] L.T. Lim, R. Auras, M. Rubino, Processing technologies for poly(lactic acid), Progress in Polymer Science, 33 (2008) 820-852.

[47] K. Prakalathan, S. Mohanty, S.K. Nayak, Polylactide/modified layered silicates nanocomposites: A critical analysis of morphological, mechanical and thermal properties, Journal of Reinforced Plastics and Composites, 31 (2012) 1300-1310.

[48] V.N. Aderikha, A.P. Krasnov, A.V. Naumkin, V.A. Shapovalov, Effects of ultrasound treatment of expanded graphite (EG) on the sliding friction, wear resistance, and related properties of PTFE-based composites containing EG, Wear, 386-387 (2017) 63-71.

[49] D.L. Burris, W.G. Sawyer, Tribological Sensitivity of PTFE/Alumina Nanocomposites to a Range of Traditional Surface Finishes, Tribology Transactions, 48 (2005) 147-153.

[50] A.S. Miavaghi, H. Kangarlou, M. Eskandarzade, Comparison Between Frictional Behavior of the Soft and Brittle Materials at Different Contact Pressures, Lebanese Science Journal, 18 (2017) 98-105.

[51] Y. Wang, F. Yan, Tribological properties of transfer films of PTFE-based composites, Wear, 261 (2006) 1359-1366. 


\section{Figure captions}

584 Fig. 1: Schematic of the experimental process.

585 Fig. 2: (a) XRD curves of clay nano-sheets (CNSs), pure Teflon (PTFE), 1, 3, and 5 wt. \% $586 \mathrm{CNSs} / \mathrm{PTFE}$ composites, (b) EDX analysis from the surface of PTFE/5 wt. \% clay nano-sheets 587 composite, (c) FE-SEM image from the surface of PTFE/5 wt. \% clay nano-sheets composite.

588 Fig. 3: (a) Stress-strain curves of pure PTFE, 1, 3, and 5 wt. \% clay nano-sheets (CNSs)/PTFE, (b) 589 elastic modulus vs. CNS content, (c) ultimate tensile strength vs. CNS content, and (d) strain at 590 UTS vs. CNS content.

591 Fig. 4: SEM images of fracture surfaces of (a) pure PTFE, (b) 1 wt. \% clay nanosheets 592 (CNSs)/PTFE, (c) 3 wt. \% CNSs/PTFE, and (d) 5 wt. \% CNSs/PTFE composites.

593 Fig. 5: Friction coefficient vs. the abrasion distance for pure PTFE, and PTFE composites 594 containing 1,3 , and 5 wt. \% clay nano-sheets.

595 Fig. 6: Temperature variations vs. the abrasion distance for pure PTFE, and PTFE composites 596 containing 1,3 , and 5 wt. \% clay nano-sheets.

597 Fig. 7: EDX analysis from the eroded surface of PTFE/5 wt. \% clay nano-sheets composite.

598 Fig. 8: SEM images of abrasive surfaces for (a) pure PTFE, and PTFE composites containing (b)

5991 , (c) 3, and (d) 5 wt. \% clay nano-sheets after the abrasion tests.

600 Fig. 9: Swarf produced after wear tests ( $a$ and b) and formation of transition films (c and d) in the 601 pure PTFE and 5 wt. \% clay nano-shets/PTFE composite, respectively. 